\title{
Engineering, Inc.
}

Engineering Services in Structural Dynamics

2850 W. Bayshore Road Palo Alto, California 94303-3843

(415) 494-7351 Fax: (415) 494-8749

$$
\angle A-S U B--96-109
$$

FORTÉ Spacecraft
Vibration Mitigation

Final Report
RECEIVED

JUN 051997

OSTI

Submitted To:

Los Alamos National Laboratory

Los Alamos, New Mexico

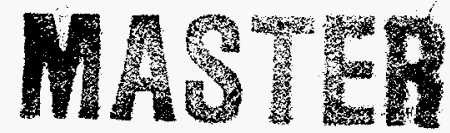

Hf

DISTRIBUTION OF THIS DOCUMENT IS UNLIMITED

Report No. 96-02-01

February 96 


\section{DISCLAIMER}

This report was prepared as an account of work sponsored by an agency of the United States Government. Neither the United States Government nor any agency thereof, nor any of their employees, make any warranty, express or implied, or assumes any legal liability or responsibility for the accuracy, completeness, or usefulness of any information, apparatus, product, or process disclosed, or represents that its use would not infringe privately owned rights. Reference herein to any specific commercial product, process, or service by trade name, trademark, manufacturer, or otherwise does not necessarily constitute or imply its endorsement, recommendation, or favoring by the United States Government or any agency thereof. The views and opinions of authors expressed herein do not necessarily state or reflect those of the United States Government or any agency thereof. 


\section{DISCLAMIER}

Portions of this document may be illegible in electronic image products. Images are produced from the best available original document. 
This report documents work that was performed by CSA Engineering for Los Alamos National Laboratory under Subcontract No. 3701P0015-35. The objective of this work was vibration mitigation of the FORTÉ structure when it is subjected to the dynamic loading associated with launch and proto-qualification testing.

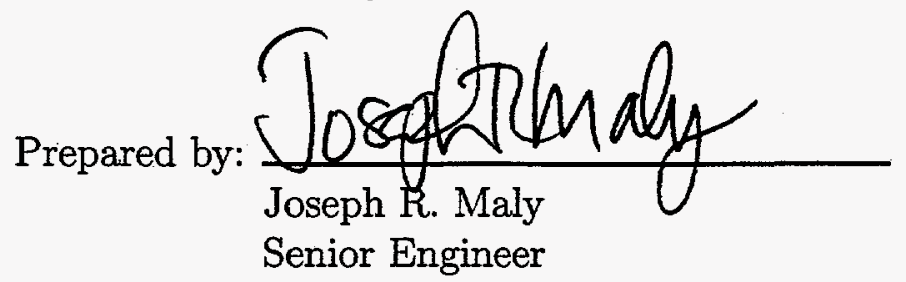




\section{Contents}

1. Introduction $\quad 1$

2. Structural Model 3

3. Passive Damping Analysis 4

3.1 Constrained-layer treatment with local deck model . . . . . . . . . 4

3.2 Damped struts and system model . . . . . . . . . . . . . . 5

4. Strut Development and Material Testing $\quad 7$

5. Direct Complex Stiffness Testing of Struts 11

6. Random Vibration Tests $\quad 13$

$\begin{array}{ll}\text { 7. Summary } & 15\end{array}$ 


\section{List of Figures}

1 FORTÉ spacecraft structure $\ldots \ldots \ldots \ldots \ldots \ldots$

2 FORTÉ random vibration proto-qualification level and measured PSD 2

3 Struts installed between FORTÉ decks . . . . . . . . . . . . 3

4 Nastran model predicted mode shapes . . . . . . . . . . . . . 3

5 Bottom deck equipment configuration and strut locations . . . . . . 7

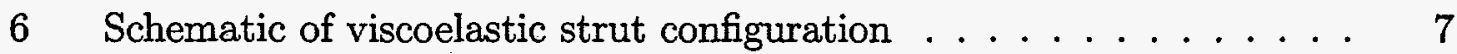

7 Finite element model of viscoelastic strut . . . . . . . . . 8

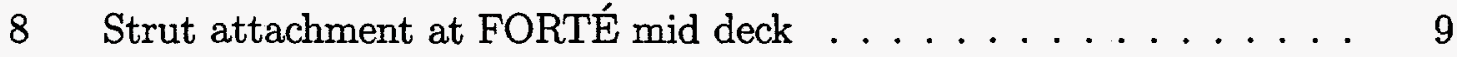

9 Temperature-frequency nomogram for FORTÉ viscoelastic material . 10

10 Isotherms of FORTÉ viscoelastic material properties at $70^{\circ} \mathrm{F} \ldots \ldots 10$

11 Schematic of strut test configuration . . . . . . . . . . 11

12 Measured strut stiffness versus frequency . . . . . . . . . . . . 12

13 Measured strut loss versus frequency $\ldots \ldots \ldots \ldots \ldots \ldots$

14 Random vibration response at scan wheel . . . . . . . . . . . 13

15 Random vibration response at corner of antenna can . . . . . . 14

16 Random vibration response at corner of mid deck . . . . . . . . 14

17 Random vibration response at center of mid deck . . . . . . . . 14

\section{List of Tables}

1 Modal frequencies from test and finite element models . . . . . . . . . 4

2 Modal strain energy percentages in important modes of FORTÉ structure 6

3 Predicted responses, RMS g's to $300 \mathrm{~Hz}$, to vertical random vibration 8 


\section{Introduction}

This report documents work that was performed by CSA Engineering, Inc., for Los Alamos National Laboratory (LANL), to reduce vibrations of the FORTÉ spacecraft by retrofitting damped structural components into the spacecraft structure. The technical objective of the work was reduction of response at the location of payload components when the structure is subjected to the dynamic loading associated with launch and proto-qualification testing.

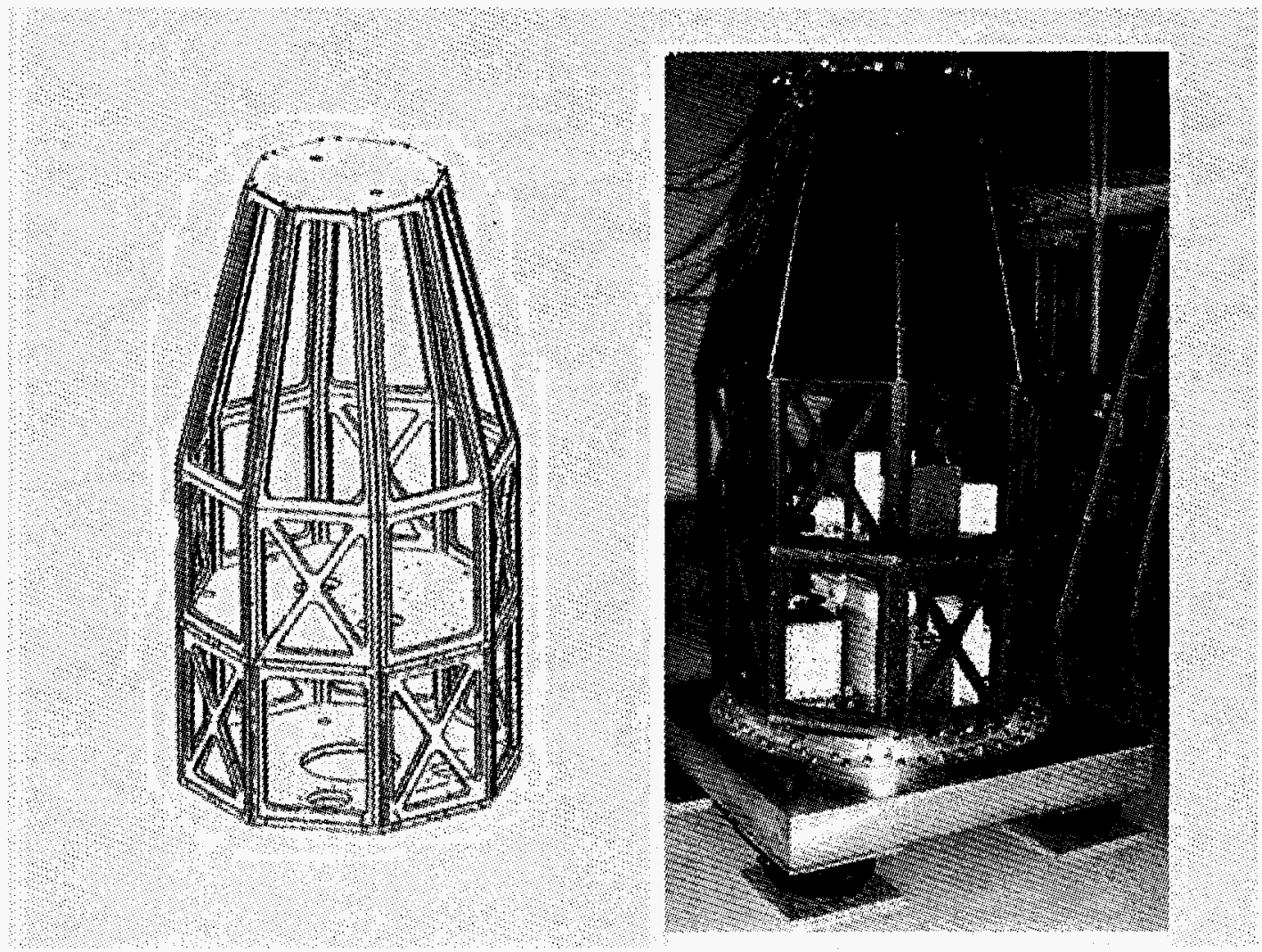

Figure 1: FORTÉ spacecraft structure

FORTÉ is a small satellite that will be placed in orbit in 1996. The structure weighs approximately $425 \mathrm{lb}$, and is roughly 80 inches high and 40 inches in diameter. It was developed and built by LANL in conjunction with Sandia National Laboratories Albuquerque for the United States Department of Energy. The FORTÉ primary structure, shown in Figure 1, was fabricated primarily with graphite epoxy, using aluminum honeycomb core material for equipment decks and solar panel substrates. Equipment decks were bonded and bolted through aluminum mounting blocks to adjoining structure. In the photograph, the structure is shown in its modal test configuration. It is mounted to the baseplate by a series of flexures similar to those which will mount the satellite to the launch vehicle separation ring. 
FORTÉ's schedule from payload conception to launch was very short, ${ }^{1}$ and satellite and payload specifications were written before the design was complete. Random vibration testing of the Engineering Model (EM) showed that acceleration PSDs for critical components on both decks would exceed proto-qualification levels, and it became evident that some form of vibration suppression was needed. Figure 2 shows the vertical random vibration proto-qualification level for mid deck payload components with the measured PSD for a key component. The structure's design and the

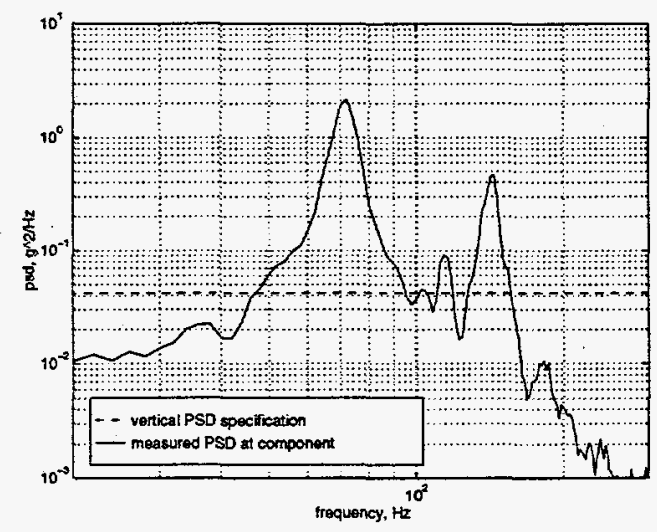

Figure 2: FORTÉ random vibration proto-qualification level and measured PSD

FORTÉ equipment layout were virtually complete by this time, so retrofit passive damping treatments were considered in conjunction with force limited random vibration testing. A structural modification was implemented, consisting of high-loss, moderate-stiffness struts installed between the bottom and mid decks of the structure. The struts are shown in Figure 3. Addition of these struts coupled the dynamics of the decks, and shearing of the struts' viscoelastic material (VEM) resulted in dissipation of vibrational energy in an important frequency band and reduction of vibration response at key spacecraft components. The viscoelastic struts were used in conjunction with force limited vibration testing, customized bracketry modified to provide isolation, and manipulation of the system mass distribution, for successful vibration mitigation of FORTÉ.

The work was divided into a number of tasks, which can be summarized as follows:

1. development of a Nastran finite element model of the FORTÉ structure,

2. selection of the best approach for implementation of passive damping,

3. design and material testing for the development of the viscoelastic struts,

4. fabrication and direct complex stiffness testing of the struts, and

5. evaluation of strut performance based on random vibration test measurements.

\footnotetext{
${ }^{1}$ The original schedule from preliminary structural design to launch was 26 months. Because of delays associated with the launch vehicle schedule, this timeline has slipped.
} 


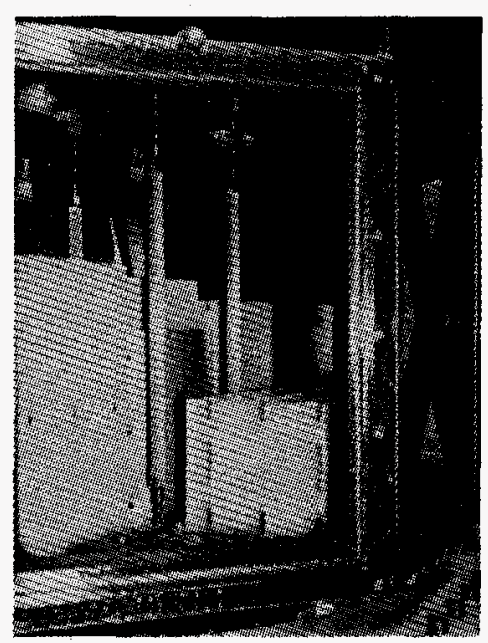

Figure 3: Struts installed between FORTÉ decks

\section{Structural Model}

A finite element (FE) model of the FORTÉ structure was developed in Nastran for prediction of system structural response with and without proposed damping treatments. The starting point for this model was LANL's existing Abaqus FE model, which was quite detailed and already "tuned" to test data. This Abaqus model was translated into Nastran, then tuned based on the Abaqus model, experimental modal data and random vibration test data provided by LANL. Boundary conditions con-
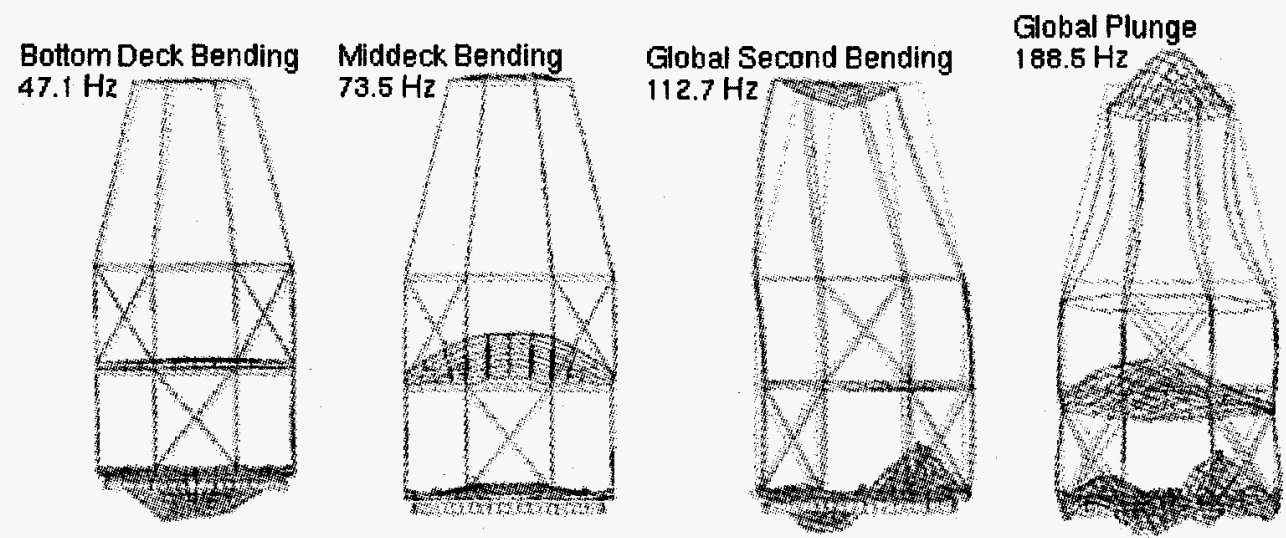

Figure 4: Nastran model predicted mode shapes

sisted of a series of translational springs around the base of the cylindrical structure, representing the flexures on which the structure was mounted on the test stand. These flexures are similar to the mounting of the satellite on the launch vehicle. 
The model was tuned to accurately represent global bending and torsion modes, bottom deck and mid deck bending modes, and global plunge modes. Table 1 lists modal frequencies observed in tests, compared with frequencies predicted with the Abaqus and tuned Nastran models. Figure 4 shows the predicted shapes for the deck

\begin{tabular}{|r|ccc|}
\hline Mode Description & Test & Abaqus & Nastran \\
\cline { 2 - 4 } & \multicolumn{3}{|c|}{ frequency, Hz } \\
\hline Antenna Can & $35-40$ & & $36.5,37.0$ \\
Global bending & 55,58 & $43.1,43.3$ & $44.3,44.5$ \\
Bottom Deck 1st Bending & 45 & 45.9 & 46.7 \\
Bottom Deck 2nd Bending & & $73.0,78.9$ & 112.7 \\
Middeck 1st Bending & 70 & 75.4 & 73.5 \\
Global 2nd Bending & 132,135 & $126.6,127.8$ & $121.2,122.4$ \\
Global Torsion & 158 & 130.3 & 126.8 \\
Global Plunge & 170 & 185.8 & 188.5 \\
\hline
\end{tabular}

Table 1: Modal frequencies from test and finite element models

bending, global second bending, and plunge modes. Modal strain energy distributions, reported by percent strain energy in various structural components for key modes of the structure, are listed in Table 2. Deck modes below $120 \mathrm{~Hz}$ and plunge modes around $170 \mathrm{~Hz}$ were specifically targeted for vibration suppression.

The tuned FE model including the struts, was delivered to Orbital Sciences Corporation (OSC), the launch integrator. CSA discussed details of the model with OSC, specifically the modeling of the viscoelastic struts.

\section{Passive Damping Analysis}

Several approaches were considered for implementation of passive damping in the FORTÉ structure, including constrained-layer damping, viscoelastic struts, and viscous struts. Constrained-layer damping and a viscoelastic strut design were developed with a component FE model of the mid deck, before the scope of the work was expanded to evaluate damping treatments based on system analysis. The final viscoelastic strut design, as well as a trade study looking at variations of a proposed viscous strut, was based on predictions using the system $\mathrm{FE}$ model.

\subsection{Constrained-layer treatment with local deck model}

The first approach considered was a constrained-layer treatment to reduce the response at the key components on the mid deck. This damping treatment targeted $10 \%$ structural damping of the local mid deck modes. Using the Modal Strain Energy 
Method, ${ }^{2} 34$ two effective design configurations were developed, each consisting of 20 mils of a high-loss viscoelastic material sandwiched between the bottom of the deck and a constraining layer. Constraining layers had to be very stiff to be effective on the stiff honeycomb deck structure, and selected constraining layers were: (1) honeycomb layup equivalent to the layup of the mid deck, and (2) 0.125-inch-thick composite.

The mid deck constrained-layer treatment was not pursued because local modes of the bottom deck and global plunge modes were unaffected. But the vibration reduction predicted by the mid deck component-level $\mathrm{FE}$ model with the constrainedlayer damping underlined the potential benefits of added passive damping and, also, the need to use the system FE model to attack the problem.

\subsection{Damped struts and system model}

The system FE model of the FORTÉ structure was used to determine modal strain energy distribution in the modes that contributed significantly to the response of the payload components. Table 2 shows the modal frequencies for important modes of the baseline model and the distribution of strain energy throughout the structure for each mode. The rationale for using high-loss struts mounted between the bottom deck and mid deck of the satellite is that, with this configuration, the strut viscoelastic material is strained in shear due to local deck bending modes as well as global bending, torsion and plunge modes. Equipment on the bottom deck is very closely spaced, and this restricted placement of the struts, but mounting the struts symmetrically around the antenna can was found to be effective. Strut mounting locations on the bottom deck are shown in Figure 5.

System analysis was performed using the Nastran model to predict performance improvements that might be expected with various viscoelastic strut configurations, and variations on a viscous strut that was proposed.

A schematic of the viscoelastic strut configuration is shown in Figure 6. Early models of this strut concept used estimates of stiffness and loss from hand calculations based on CSA's experience with VEMs. This model was refined by using a component

\footnotetext{
${ }^{2}$ To optimize a constrained-layer treatment, application of this method amounts to determining the material properties and thickness of both the VEM and constraining layer such that the amount of strain energy in the VEM for the mode(s) of interest is maximized. Modal strain energy can be used to estimate modal damping, i.e., the modal damping of a structure is approximated by the sum of the products of the loss factor of each material and the fraction of strain energy in that material for each mode. Specifically, the system loss is given by$$
\eta^{(r)}=\sum_{i=1}^{M} \eta_{i} \frac{S E_{i}^{(r)}}{S E^{(r)}}
$$

${ }^{3}$ Johnson, C.D., and Kienholz, D.A., "Finite Element Prediction of Damping in Structures with Constrained Viscoelastic Layers," AIAA Journal, Vol. 20, No. 9, September 1982.

${ }^{4} \mathrm{Johnson}$, C.D., and Kienholz, D.A., "Prediction of Damping in Structures with Viscoelastic Materials," MSC/NASTRAN User's Conference Proceedings, March 1983.
} 


Mode number
Frequency, Hz
FLEXURE SPRINGS
MIDDECK
BOTTOM DECK
BEAMS
BASE
PANELS
TOP DECK
ALUMINUM INSERTS
ANTENNA CAN SPRINGS
MOde number
Frequency, Hz
FLEXURE SPRINGS
MIDDECK
BOTTOM DECK
BEAMS
BASE
PANELS
TOP DECK
ALUMINUM INSERTS
ANTENNA CAN SPRINGS

$\begin{array}{rrrrrrrrrr}1 & 2 & 3 & 4 & 5 & 6 & 7 & 8 & 9 & 10 \\ 36.5 & 36.9 & 44.2 & 44.4 & 46.6 & 73.4 & 108.9 & 112.7 & 121.2 & 122.3 \\ & & & & & & & & & \\ 4.3 & 4.8 & 11.0 & 10.5 & 3.5 & 3.4 & 0.3 & 2.5 & 2.8 & 3.6 \\ 0.3 & 0.3 & 0.7 & 0.7 & 1.1 & 63.4 & 0.6 & 0.4 & 2.6 & 2.2 \\ 55.3 & 53.0 & 39.6 & 39.6 & 61.3 & 8.2 & 0.6 & 67.8 & 12.7 & 23.4 \\ 13.1 & 13.9 & 15.2 & 13.4 & 13.3 & 20.0 & 2.0 & 4.1 & 23.7 & 16.8 \\ 2.0 & 2.2 & 4.6 & 4.4 & 4.7 & 1.1 & 0.1 & 2.7 & 4.8 & 5.4 \\ 7.2 & 8.2 & 13.1 & 12.6 & 4.3 & 2.7 & 0.5 & 8.8 & 50.5 & 43.2 \\ 0.0 & 0.0 & 0.0 & 0.0 & 0.0 & 0.1 & 95.8 & 0.3 & 0.1 & 0.1 \\ 2.3 & 2.2 & 2.7 & 2.2 & 6.1 & 0.6 & 0.1 & 1.3 & 2.0 & 2.1 \\ 15.5 & 15.4 & 13.0 & 16.7 & 5.6 & 0.5 & 0.1 & 12.0 & 1.0 & 3.2 \\ & & & & & & & & & \\ 11 & 12 & 13 & 18 & 19 & 20 & 21 & 23 & 24 & 25 \\ 127.7 & 133.0 & 135.3 & 158.6 & 161.6 & 165.6 & 168.3 & 188.5 & 194.6 & 200.2 \\ & & & & & & & & & \\ 3.3 & 1.6 & 6.8 & 1.5 & 4.4 & 2.1 & 4.0 & 8.5 & 5.5 & 3.1 \\ 1.9 & 1.3 & 0.4 & 0.3 & 14.8 & 25.5 & 26.8 & 7.3 & 12.4 & 22.7 \\ 13.1 & 60.3 & 75.9 & 52.7 & 54.1 & 40.0 & 45.5 & 45.9 & 27.6 & 19.3 \\ 20.0 & 6.8 & 3.2 & 19.3 & 9.9 & 10.0 & 6.3 & 12.4 & 13.0 & 14.1 \\ 4.8 & 1.0 & 1.8 & 1.1 & 4.0 & 1.1 & 1.6 & 5.7 & 3.4 & 1.4 \\ 54.5 & 17.2 & 5.7 & 20.4 & 10.7 & 6.5 & 3.0 & 17.1 & 32.3 & 38.2 \\ 0.0 & 0.1 & 0.0 & 0.3 & 0.2 & 0.3 & 0.2 & 0.6 & 0.3 & 0.1 \\ 1.9 & 0.9 & 1.0 & 0.7 & 1.3 & 0.8 & 0.8 & 2.4 & 1.5 & 0.5 \\ 0.3 & 10.8 & 5.2 & 3.6 & 0.6 & 13.6 & 11.9 & 0.1 & 4.0 & 0.7\end{array}$

Table 2: Modal strain energy percentages in important modes of FORTÉ structure

level FE model of the strut, shown in Figure 7, which included springs to account for compliance in the strut end fittings. ${ }^{5}$ This component model was tuned to results from component-level direct complex stiffness testing described in Section 5 of this report. The tuned component FE model of the strut could then be modified to investigate different strut configurations, with variations on the VEM thickness and/or VEM shear area.

For each strut configuration of interest, the component FE model was used to generate tabular listings of strut stiffness and strut loss versus frequency. These vectors were then used to model the struts in the system FE model, i.e., the struts were modeled as beam elements having the appropriate frequency-dependent stiffness and loss characteristics. Nastran provides for the frequency dependent material behavior in random response analysis, so the FORTÉ system model was subjected to the proto-qualification random vibration inputs, with the struts installed in the model, and response predictions were computed for comparison with baseline response and other strut designs.

Viscous struts were modeled as beam elements in parallel with viscous dashpots. Stiffness of $54 \mathrm{lb} /$ in and damping of $4.4 \mathrm{lb}-\mathrm{sec} /$ in were included as specified by the strut vendor. Other dashpot constants ranging from 0.8 to $110 \mathrm{lb}-\mathrm{sec} /$ in were also analyzed.

\footnotetext{
${ }^{5}$ Compliance in the struts at the deck-attachment locations is unwanted but unavoidable. Part of the challenge of this strut design was to minimize the compliance of the strut end fittings, thereby increasing the modal strain energy in the VEM of the struts.
} 


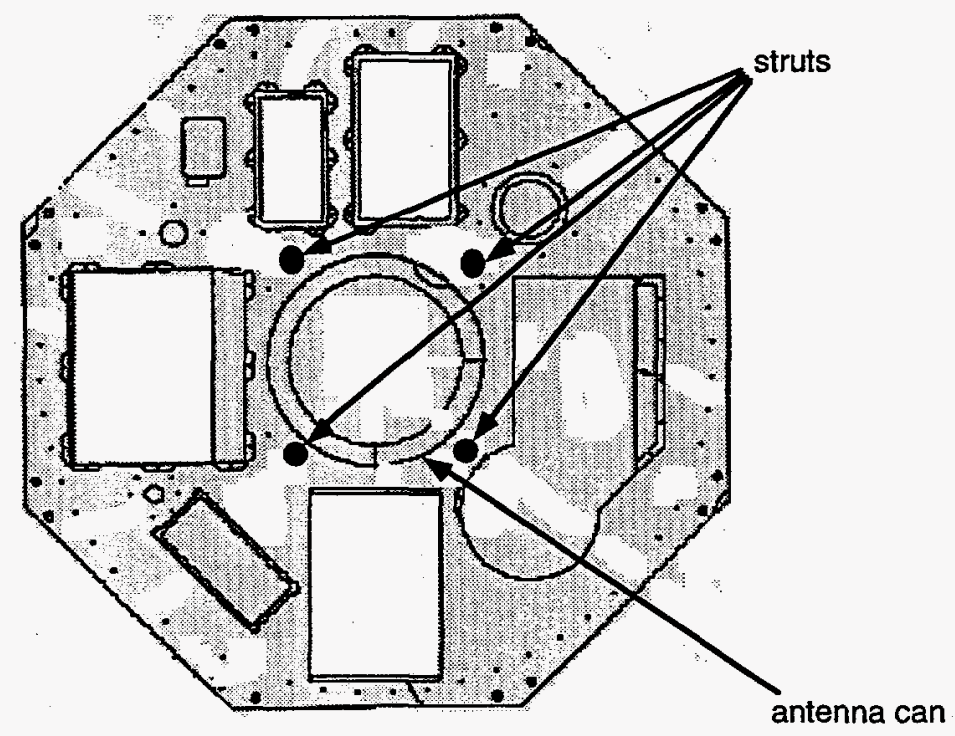

Figure 5: Bottom deck equipment configuration and strut locations

Middeck

Bottom Deck

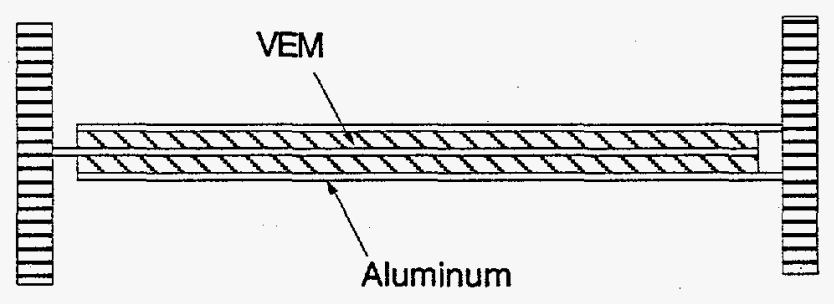

Figure 6: Schematic of viscoelastic strut configuration

Table 3 gives RMS response predictions, in g's, for various strut designs, subjected to the vertical proto-qualification-level random vibration input. Both the viscous and viscoelastic struts were found to produce favorable results, so selection of the appropriate treatment was based on fabrication and in-service concerns. Ultimately, the viscoelastic struts were preferred because of the simplicity of fabrication and LANL's reluctance to include viscous fluids in a spacecraft application.

\section{Strut Development and Material Testing}

As described in Section 3, trade studies were performed with the FE model to determine the appropriate stiffness and loss characteristics of the struts. Analytical predictions of strut stiffness and loss were correlated with direct complex stiffness 


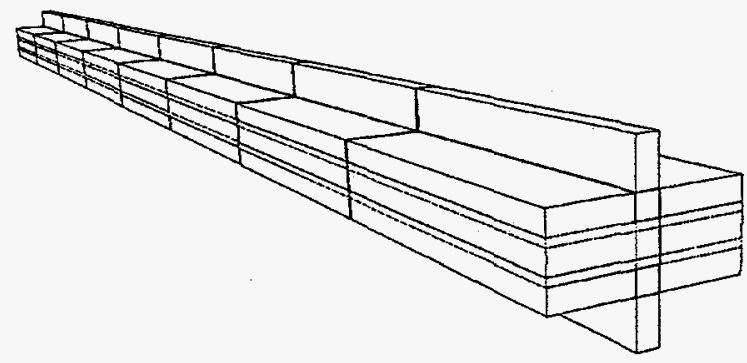

Figure 7: Finite element model of viscoelastic strut

\begin{tabular}{|c|c|c|c|c|c|c|c|c|}
\hline & & visc & $\begin{array}{l}\text { elastic } \\
\text { oss = } \\
\text { tiffneos }\end{array}$ & ruts & $\begin{array}{r}v \\
\text { stiff } \\
a t n u t d\end{array}$ & $\begin{array}{l}\text { ous st } \\
\text { ss }=5\end{array}$ & $\begin{array}{l}\text { s } \\
\mathrm{d} / \text { in } \\
\text { fficie }\end{array}$ & \\
\hline & & strut & tiffness & & strut d & iping & fficie & -s/in \\
\hline & baseline & 50000 & 30000 & 10000 & 0.88 & 4.4 & 22.0 & 110.0 \\
\hline input & 1.55 & 1.55 & 1.55 & 1.55 & 1.55 & 1.55 & 1.55 & 1.55 \\
\hline center of mid deck & 7.69 & 4.01 & 3.74 & 4.60 & 6.29 & 4.30 & 3.15 & 3.79 \\
\hline scan wheel, inner & 6.76 & 3.30 & 3.08 & 3.87 & 5.71 & 3.81 & 2.74 & 3.40 \\
\hline scan wheel, outer & 5.33 & 2.53 & 2.32 & 2.92 & 4.53 & 2.97 & 2.33 & 3.38 \\
\hline corner of mid deck & 4.23 & 3.70 & 3.59 & 4.04 & 3.81 & 3.69 & 3.42 & 3.26 \\
\hline corner of antenna can & 2.28 & 3.00 & 2.55 & 2.87 & 2.16 & 1.94 & 2.26 & 3.51 \\
\hline corner lower deck & 2.17 & 1.97 & 1.92 & 2.10 & 2.34 & 2.26 & 2.11 & 2.06 \\
\hline
\end{tabular}

Table 3: Predicted responses, RMS g's to $300 \mathrm{~Hz}$, to vertical random vibration

test results from an initial design of the strut that was fabricated and tested. The figures of merit for optimization of the design were (1) RMS response at the sensitive equipment locations and (2) reduction of peak response levels to the specification level to which they were tested, i.e., $0.042 \mathrm{~g}^{2} / \mathrm{Hz}$.

Four damped struts plus one spare were built. The viscoelastic material, 3M 9473 pressure-sensitive adhesive, was configured with a thickness of 0.040 inches, and a shear area of about 18 square inches. Material testing was performed to quantify the mechanical properties and outgassing characteristics. LANL designed the metallic portion of the link, including the interface joints at the bottom and mid decks of the structure. CSA assisted LANL in the fabrication, and one of the struts was tested at CSA to measure its complex stiffness, i.e., stiffness and damping as functions of frequency. These strut parameters were provided to LANL for inclusion in the system model of the FORTÉ structure. CSA was present at LANL during the testing of the damping treatment on the FORTÉ structure, and provided consultation with regard to the treatment implementation. Figure 8 shows a closeup of the strut attachment at FORTÉ mid deck.

\section{Material testing - mechanical properties}

Viscoelastic material properties are highly dependent on both frequency and temperature. The FORTÉ temperature environment is benign, i.e., both launch and 


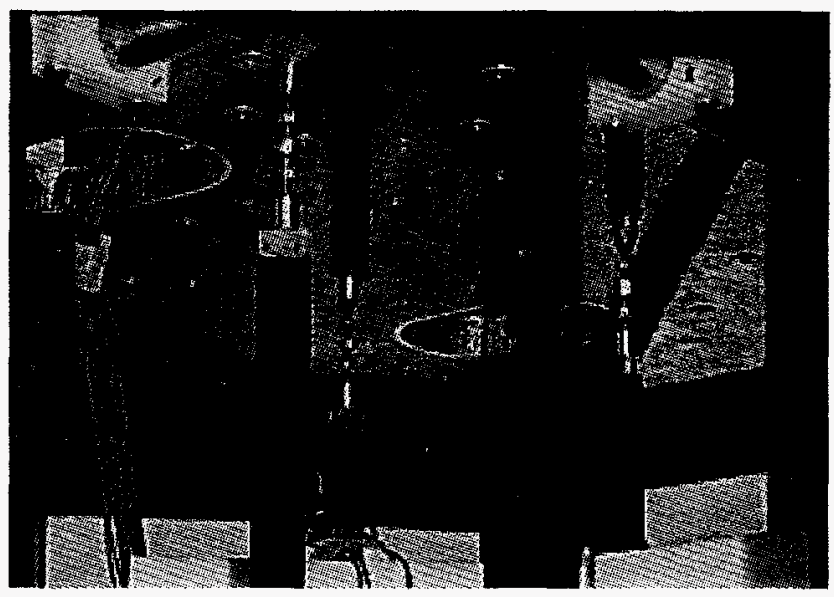

Figure 8: Strut attachment at FORTÉ mid deck

testing environments are thermally controlled, so temperature variation is not an issue. But knowledge of the material mechanical properties as functions of frequency was critical to development of the struts. The selected VEM, 3M 9473, was characterized, and the temperature-frequency nomogram that describes the relevant mechanical properties, shear modulus and loss factor, is shown in Figure 9. This nomogram conveys information about the material's shear modulus and loss factor as functions of temperature $\left(-25^{\circ} \mathrm{F}\right.$ to $185^{\circ} \mathrm{F}$ ) and frequency (to $600 \mathrm{~Hz}$ ). Isotherms of shear modulus and loss factor for the FORTÉ strut material at $70^{\circ} \mathrm{F}$, are plotted versus frequency in Figure 10.

\section{Material testing - outgassing}

Viscoelastic materials are more prone to outgassing than many spacecraft materials such as aluminum or composites. ${ }^{6}$ Outgassing was not considered a major issue for the FORTÉ spacecraft, but for completeness, and to insure that this did not become an issue at some point in the future, the selected material was characterized for outgassing by Nusil Technology of Carpinteria, California. From prior experience, it was known that this material is usually acceptable with regard to out-

\footnotetext{
${ }^{6}$ Outgassing is the process by which gas is emitted from a solid which has been subjected to an increase in temperature or a decrease in pressure. A standard test method has been developed by the American Society for Testing and Materials (ASTM) to quantify outgassing behavior. A material sample is placed in a solid copper enclosure with a 0.25 -inch-diameter exit port as the only escape route for gas produced by the temperature and vacuum conditions. The sample is heated to $125^{\circ} \mathrm{C}\left(257^{\circ} \mathrm{F}\right)$ and maintained at this temperature in a vacuum of $10^{-6}$ Torr for 24 hours. The volatile materials are driven off through the exit port to a chromium-plated collector maintained at $25^{\circ} \mathrm{C}\left(77^{\circ} \mathrm{F}\right)$ in direct line of sight of the exit port. The \%TML of the sample is determined as the percentage change from the sample weights measured before and after the procedure, and the \%CVCM is calculated by measuring the difference between the weight of the clean collector and the weight of the collector with condensed materials and calculating this difference as a percentage of the starting mass of the sample.
} 


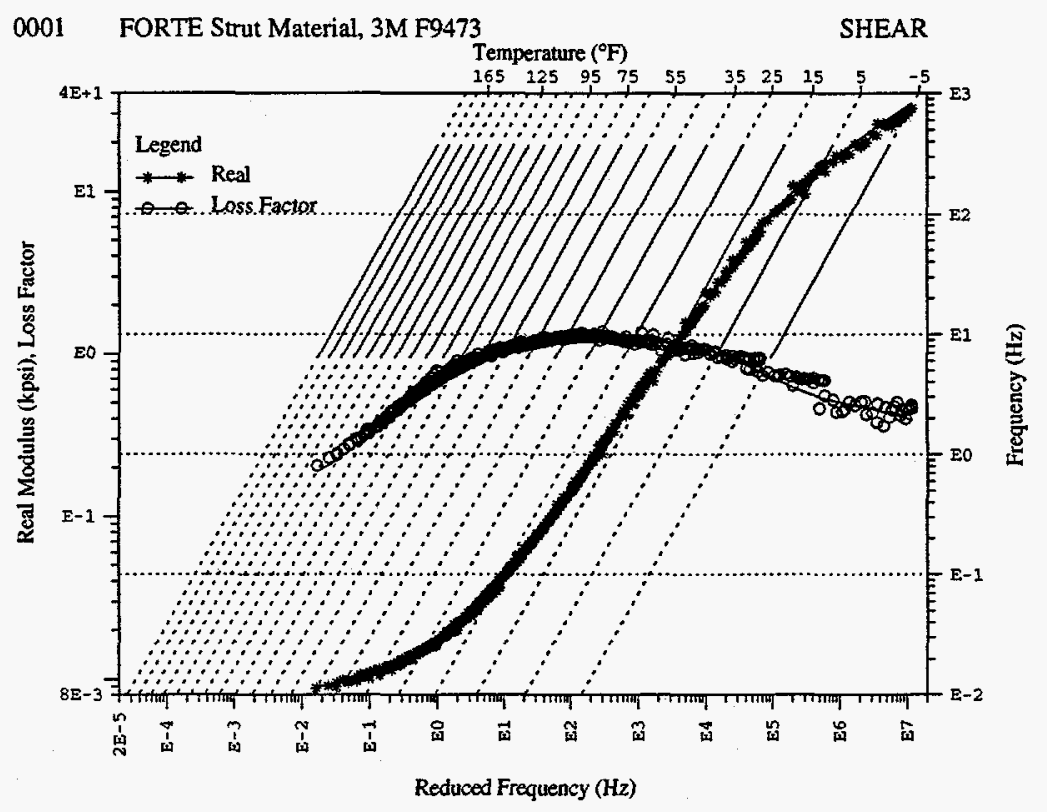

Figure 9: Temperature-frequency nomogram for FORTÉ viscoelastic material

gassing, but, as with viscoelastic material properties, outgassing behavior can vary from lot to lot. Tests were performed in accordance with ASTM E-595 and NASA SP-R-0022A specifications. The total mass loss (TML) was measured at $0.68 \%$, and the collected volatile condensible material (CVCM) was $0.03 \%$. The NASA standards for acceptable spacecraft materials are TML of $1.00 \%$, and CVCM is $0.10 \%$.

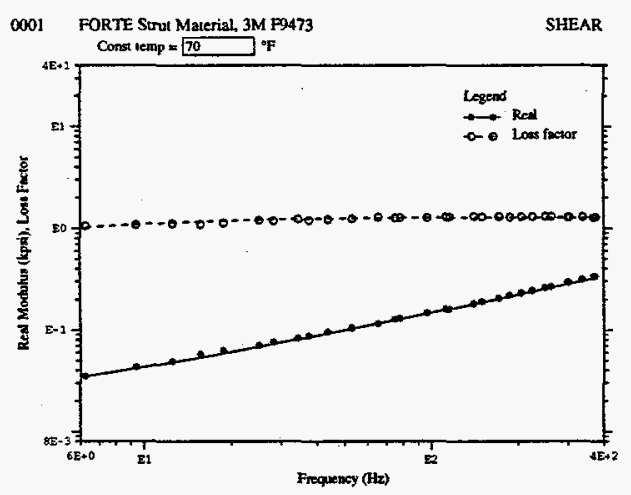

Figure 10: Isotherms of FORTÉ viscoelastic material properties at $70^{\circ} \mathrm{F}$ 


\section{Direct Complex Stiffness Testing of Struts}

Strut stiffness and loss of the FORTÉ struts were measured by means of a test procedure referred to as direct complex stiffness testing. To understand this test method, consider a static stiffness measurement, which consists of applying a known load to a structure and measuring the resulting displacement. Static stiffness is simply the load divided by the displacement. Complex stiffness measurements are needed to characterize a damped structure, because the load (or stress) is out of phase with the displacement (or strain). The amount of phase is determined by the damping in the structure. For complex stiffness measurement of a strut, a random force having the desired frequency content is applied axially, and the resulting dynamic displacement is measured, including the phase angle between the input force and the output displacement. From this complex stiffness measurement, the "real" stiffness of the strut is simply the real part of the complex stiffness, and the loss, or structural damping, of the strut, is the ratio of the imaginary stiffness to the real stiffness.

The test rig for characterization of the struts consisted of virtually rigid "book ends" (mounting brackets to support the strut under test) bolted to a large work plate, and a hydraulic shaker positioned to excite the strut axially. A strain gage type load cell was mounted in series with the strut. A schematic of the test configuration is shown in Figure 11. The strut was excited axially with a controlled, baseband random
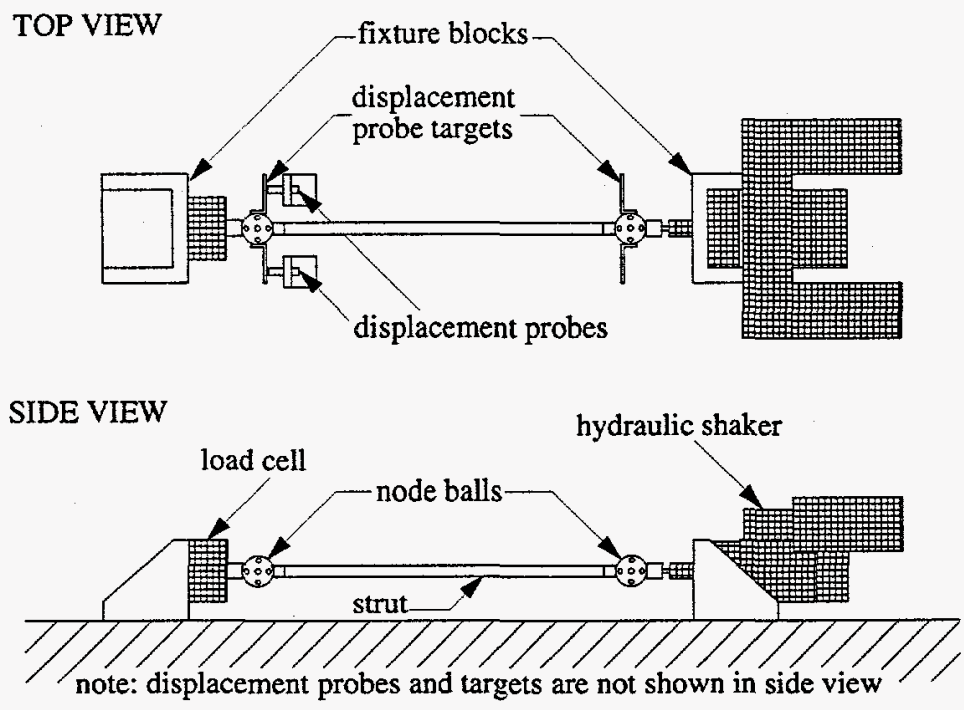

Figure 11: Schematic of strut test configuration

force, and axial displacement was measured with eddy current probes referencing the angle-bracket "flags" attached to each node ball (as shown). Complex stiffness was calculated by dividing the input force by the measured displacement.

Results of the strut complex stiffness testing are shown in Figures 12 and 13. 
Complex stiffness was measured at various input force levels, and Figure 12 shows measurements taken at $100 \mathrm{lbf}, 200 \mathrm{lbf}$, and $300 \mathrm{lbf}$. Measured strut loss versus frequency is shown in Figure 13.

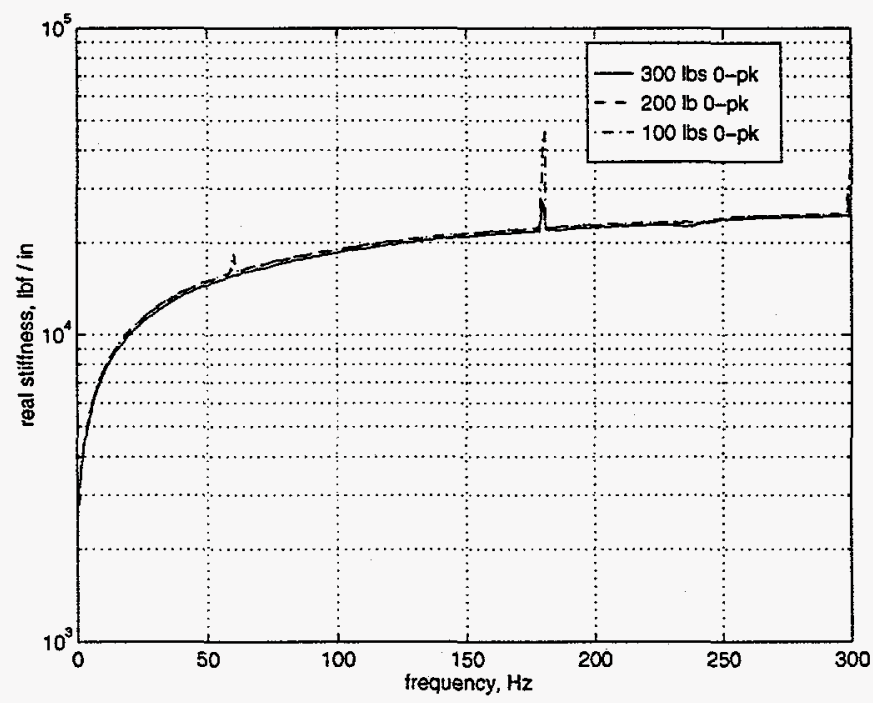

Figure 12: Measured strut stiffness versus frequency

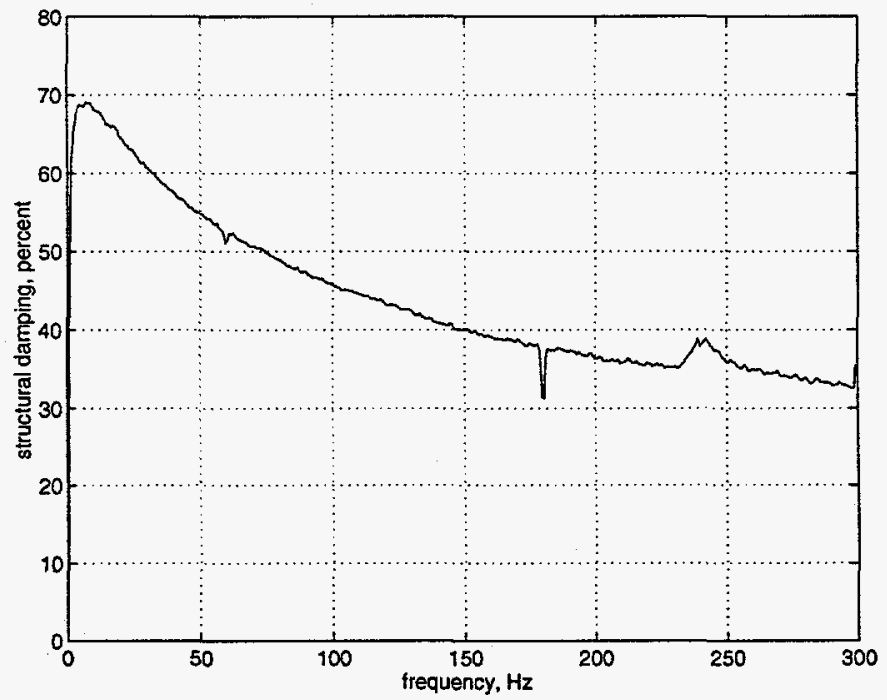

Figure 13: Measured strut loss versus frequency 


\section{Random Vibration Tests}

Random vibration testing was performed at LANL as part of proto-qualification testing for FORTÉ. The figures of merit for vibration mitigation design were based on measured responses when the structure is subjected to random vibration testing: (1) minimization of RMS responses at sensitive equipment, and (2) reduction of peak responses to $0.042 \mathrm{~g}^{2} / \mathrm{Hz}$, the level to which equipment was tested. It was especially important to reduce peak levels below $0.042 \mathrm{~g}^{2} / \mathrm{Hz}$ in frequency bands where component resonances were present.

Figures 15 through 17 present comparison plots of PSD response at key locations on the structure with and without the viscoelastic struts. Figure 14 shows responses at the scan wheel, a very important payload component. The reduction of 3 orders of magnitude around $70 \mathrm{~Hz}$ shown in this plot was especially significant, because this component is known to have an internal resonance around $65 \mathrm{~Hz}$. Response levels above $100 \mathrm{~Hz}$ for the scan wheel were reduced with force limited testing. Figure 15 shows responses at the corner of the antenna can on the bottom deck. Figure 16 shows responses at the corner of the mid deck and Figure 17 gives responses at the center of the mid deck.

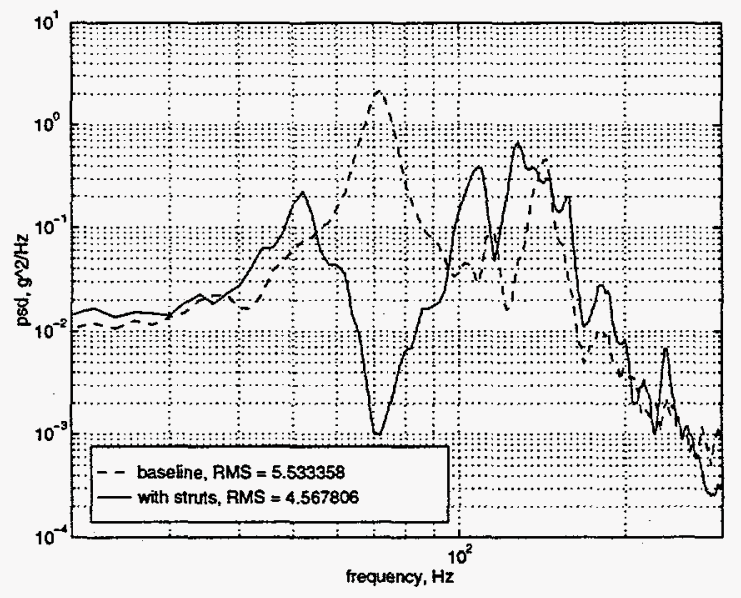

Figure 14: Random vibration response at scan wheel 


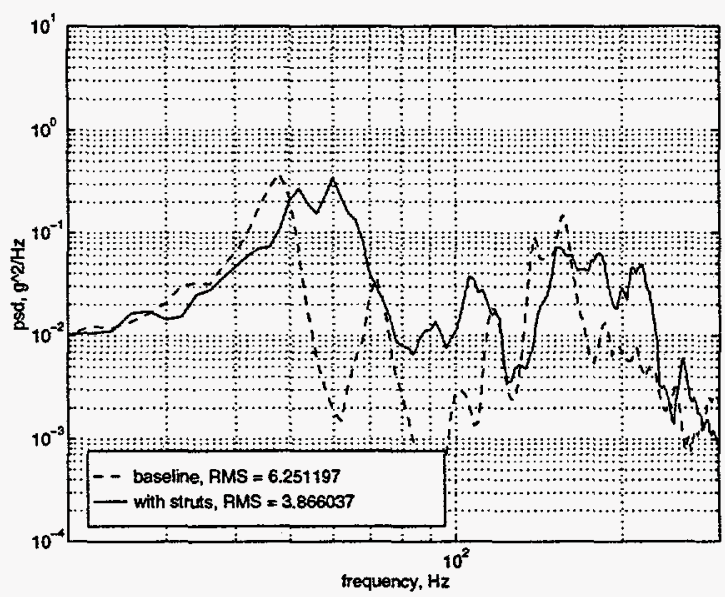

Figure 15: Random vibration response at corner of antenna can

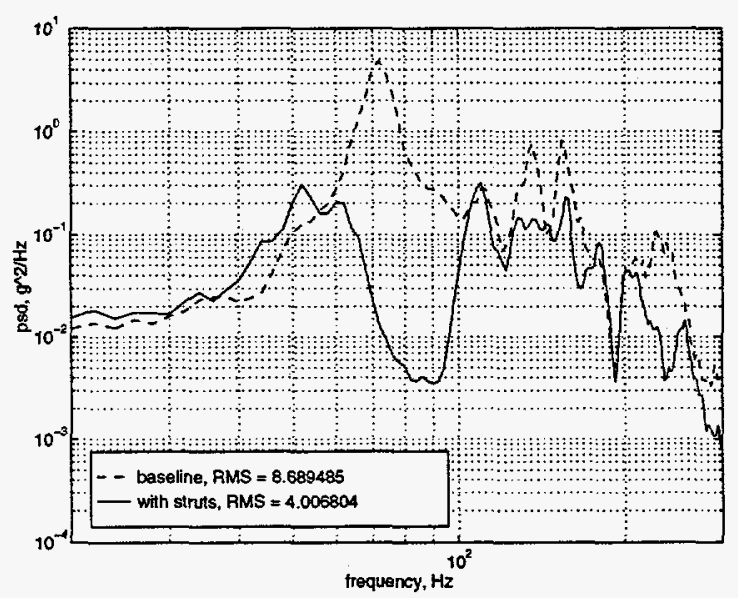

Figure 16: Random vibration response at corner of mid deck

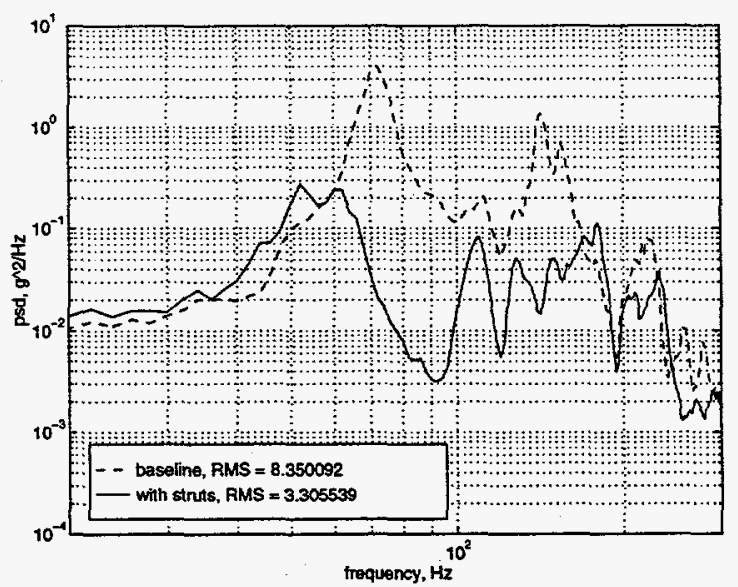

Figure 17: Random vibration response at center of mid deck 


\section{Summary}

CSA Engineering, Inc., performed analysis, design, and testing work for Los Alamos National Laboratory, as part of a program to reduce vibrations of the FORTÉ spacecraft. The technical objective of the work was reduction of response at the location of payload components when the structure is subjected to the dynamic loading associated with launch and proto-qualification testing. The end product of the work was a set of viscoelastic struts that were fabricated, tested, and installed in the FORTÉ structure.

CSA developed a Nastran finite element model of the FORTÉ structure, worked with LANL to select the best approach for implementation of passive damping, performed analytical trade studies with the system FE model and a strut FE model to determine the best design configuration for a viscoelastic strut, performed material testing, assisted in strut fabrication, performed direct complex stiffness testing of the struts, and assisted in evaluation of strut performance based on random vibration test measurements.

Addition of the viscoelastic struts coupled the dynamics of the decks, and shearing of the viscoelastic material resulted in dissipation of vibrational energy in an important frequency band and reduction of vibration response at key spacecraft components. The viscoelastic struts were used in conjunction with force limited vibration testing, customized bracketry modified to provide isolation, and manipulation of the system mass distribution, for successful vibration mitigation of FORTÉ. 